\title{
Yeast HMG proteins NHP6A/B potentiate promoter-specific transcriptional activation in vivo and assembly of preinitiation complexes in vitro
}

\author{
Tanya T. Paull, ${ }^{1,3}$ Michael Carey,,2 and Reid C. Johnson ${ }^{1,2,4}$ \\ ${ }^{1}$ Molecular Biology Institute and ${ }^{2}$ Department of Biological Chemistry, School of Medicine, University of California, Los \\ Angeles, Los Angeles, California 90095-1737 USA
}

\begin{abstract}
Nonhistone proteins 6A and 6B (NHP6A/B) are nonsequence-specific DNA-binding proteins from Saccharomyces cerevisiae that are related structurally and functionally to the mammalian high mobility group proteins 1 and 2. These DNA architectural proteins distort DNA structure severely and have been shown to promote assembly of specialized recombination complexes. Here we show that the yeast NHP6A/B proteins are required for the induction of a subset of genes transcribed by RNA polymerase II (pol II). Activation of the CUP1, CYC1, GAL1, and DDR2 genes was decreased or abolished completely in the $\Delta n h p 6 A / B$ strain. No significant change in basal expression was observed for any of the 10 genes examined. Analysis of chimeric gene constructs localized the regions dependent on NHP6A/B to be primarily at the core promoters, although the GAL1 UAS also requires NHP6A/B for activity. In vitro, NHP6A stimulated transcription by pol II at the GAL1 promoter three- to fivefold above the level of activation by GAL4-VP16 alone. Gel mobility shift assays showed that NHP6A promotes the formation of a complex with TBP and TFIIA at the TATA box that has enhanced affinity for TFIIB.
\end{abstract}

[Key Words: High mobility group proteins; transcription; Saccharomyces cerevisiae; DNA bending]

Received July 17, 1996; revised version accepted September 12, 1996.

Regulated DNA transactions often require the construction of large, multicomponent nucleoprotein complexes. In some cases, the formation of these complexes entails the actions of auxiliary DNA-binding proteins that bend or kink the DNA strands into conformations that facilitate interactions between other proteins. These DNAbending proteins have been called "architectural" or "assembly" factors because of their structural role in this process, and have been studied most extensively in prokaryotic recombination reactions. For instance, the prokaryotic nucleoid-associated protein HU facilitates the formation of the invertasome, an intermediate complex in the Hin DNA inversion reaction (Haykinson and Johnson 1993). The length of DNA in one of the loops constrained by the Hin recombinase and the host Fis protein determines the requirement for HU (Haykinson and Johnson 19931, suggesting that the primary role of this factor is to alleviate the torsional rigidity of the

${ }^{3}$ Present address: Laboratory of Molecular Biology, National Institute of Diabetes and Digestive and Kidney Diseases, National Institutes of Health, Bethesda, Maryland 20892 USA.

${ }^{4}$ Corresponding author.
DNA helix and allow the assembly of the other proteins into the invertasome.

Eukaryotic transcription reactions involve the assembly of elaborate nucleoprotein structures that are also likely to involve architectural proteins that function in a sequence- or nonsequence-specific manner (Tiian and Maniatis 1994). To identify such proteins we searched for nonsequence-specific activities from mammalian extracts that could substitute for $\mathrm{HU}$ in promoting assembly of model recombination complexes and found that high-mobility group proteins 1 and 2 (HMG1/2) were very active in assembling active Hin invertasomes. HMG1/2 can also replace HU in stimulating transpososome complexes in the bacteriophage $\mathrm{Mu}$ transposition reaction (Lavoie and Chaconas 1994), and can even substitute for the sequence-specific binding integration host factor (IHF) protein in assembling intasome complexes on bacteriophage $\lambda$ recombination substrates (Segall et al. 1994). HMG1/2 bind DNA with little sequence specificity and are even more active than $\mathrm{HU}$ in bending DNA in circularization assays (Paull et al. 1993; Pil et al. 1993). Thus, these abundant chromatin-associated proteins could function as the mammalian equivalents of 
HU and contribute to the assembly of nucleoprotein complexes in eukaryotic cells.

HMG1/2 were discovered more than 20 years ago /for review, see Johns 1982), but despite extensive in vitro characterizations, the specific functions of HMG1/2 remain largely unknown. The two highly charged proteins have been shown to bind preferentially to cruciform DNA (Bianchi et al. 1989) and to cis-platinated DNA (Pil and Lippard 1992) in vitro, but the relevance of these activities in vivo has not been established. HMG1/2 have also been shown to affect the assembly of nucleosomes and the organization of chromatin structure in vitro (Bonne-Andrea et al. 1984; Nightingale et al. 1996). There have also been reports of stimulatory effects of HMGl/2 on transcription in eukaryotic cell extracts, showing that one or both of the proteins stimulate the formation of initiation complexes (Tremethick and Molloy 1988; Singh and Dixon 1990; Shykind et al. 1995), but that they do not function directly as transcriptional activators (Landsman and Bustin 1991). In contrast, other reports have shown that HMGl/2 proteins act as repressors of polymerase II (pol II)-mediated transcription in vitro (Ge and Roeder 1994; Stelzer et al. 1994).

A major obstacle to the study of HMG1/2 in vivo has been the lack of a convenient genetic model. To address this problem, we identified proteins with similar biochemical characteristics to those of HMG1/2 from Saccharomyces cerevisiae using the Hin-catalyzed DNA inversion reaction as a functional assay (Paull and Johnson 1995). The factors identified in this screen were nonhistone proteins $6 \mathrm{~A}$ and $6 \mathrm{~B}(\mathrm{NHP} 6 \mathrm{~A} / \mathrm{B})$, two of a set of proteins identified initially because of their solubility characteristics (Kolodrubetz and Burgum 1990). NHP6A/B contain the "HMG box" DNA-binding motif, which is present in other HMGl/2 homologs as well as in more distantly related sequence-specific DNA-binding factors (for review, see Landsman and Bustin 1993; Grosschedl et al. 1994). The HMG box domains of NHP6A/B are $45 \%$ and $40 \%$ identical to domain B of rat HMG1, respectively (Kolodrubetz and Burgum 1990), the structure of which has been solved by NMR and shown to contain a novel L-shaped domain of three tightly packed alpha helices (Read et al. 1993; Weir et al. 1993). The NMR structures of two sequence-specific HMG domain proteins SRY, the testes-determining factor, and LEF-1, a lymphoid enhancer-binding protein, bound to DNA have also been solved (Love et al. 1995; Werner et al. 1995). These structures reveal that the distortion of the DNA helix by these proteins, leading to overall bending of $80^{\circ}$ and $130^{\circ}$, respectively, occurs by partial intercalation of an amino acid side chain into the minor groove (for review, see Werner et al. 1996).

Here we report the first characterization of the effects of HMGl/2-like proteins on transcription by pol II in vivo. Using yeast strains deficient in NHP6A/B, we have measured the expression of many genes and found that a subset are dependent on NHP6A/B for induction. Using chimeric constructs, we found that the core promoter regions dictate the requirement for NHP6A/B activity. In agreement with this observation, in vitro gel mobility assays show that NHP6A stimulates the formation of DNA complexes between a core promoter and TATAbinding protein (TBP) and TFIIA, one of which is bound preferentially by TFIIB. We propose that the nucleoprotein complex that forms on TATA box sequences in eukaryotic cells may be one of the intermediates that depends on NHP6A/B for efficient assembly and activation.

\section{Results}

\section{NHP6A / B facilitate activated transcription of specific} promoters in vivo

To study the cellular roles of NHP6A/B we constructed yeast strains containing null alleles of each gene separately and in combination. Strains lacking either NHP6A or NHP6B are unaffected for growth, whereas the double mutant is temperature-sensitive at $38^{\circ} \mathrm{C}$, as reported previously (Costigan et al. 1994). At $30^{\circ} \mathrm{C}$, the $\Delta n h p 6 A / B$ strain grows slowly and forms colonies of heterogeneous size. The severity of the double mutant phenotype is consistent with the abundance of NHP6A/B in S. cerevisiae. There are $\sim 50,000$ to 70,000 molecules of NHP6A per haploid yeast cell, as estimated by immunoblotting of yeast spheroplast and whole cell extracts (data not shown). This amount would correspond to $\sim 1$ molecule of NHP6A for every 1-2 nucleosomes, which is similar to the value of $1 \mathrm{HMGl} / 2$ per 3 nucleosomes reported for mammalian cells (Kuehl et al. 1984). The levels of NHP6B were $\sim 10 \%$ of the NHP6A levels, which is consistent with the relative amounts of NHP6A/B transcripts observed previously (Kolodrubetz and Burgum 1990).

We measured the expression of a number of pol IItranscribed genes by LacZ fusion activity or by primer extension in both the wild-type and $\triangle n h p 6 A / B$ strains, as shown in Figure 1 and Table 1. In general, no significant change in basal transcription levels in the mutant cells was observed, but the ability to respond to transcriptional activators was severely diminished for a subset of the genes tested. For example, a CUP1-LacZ reporter construct was induced $\sim 10$-fold in the wild-type strain by exposure to $1 \mathrm{mM} \mathrm{CuSO}_{4}$, but the $\triangle n h p 6 A / B$ strain yielded essentially no induction (Fig. 1A). Activation of a GAL1-LacZ gene was also impaired in the mutant strain, which exhibited only $1.5 \%$ of the wild-type level of $\beta$-galactosidase under inducing conditions (Fig. 1B and Table 1). A CYCl-LacZ construct was also not activated in the $\triangle n h p 6 A / B$ strain (Fig. 1C), but induction of a PHO5-LacZ construct was similar in both strains, with the mutant cells showing $80 \%$ of $\beta$-galactosidase levels as compared with wild-type cells (Fig. 1D). The DDR2 gene was induced $\sim 13$-fold by the DNA-damaging agent methyl methanesulfonate in a wild-type strain, but yielded only $\sim 2$-fold induction in the $\triangle n h p 6 A / B$ strain (Fig. $1 \mathrm{E}$ and Table 1). In contrast, activated expression of the URA3 gene by uracil starvation is reduced only by $\sim 50 \%$ in the $\triangle n h p 6 A / B$ strain (Fig. $1 \mathrm{~F}$ and Table 1). 
A

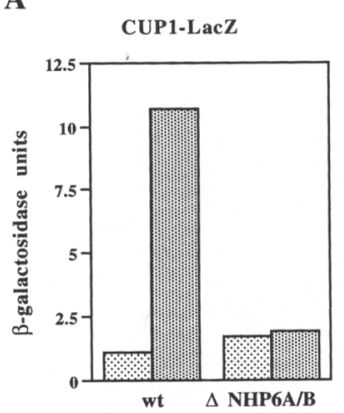

B

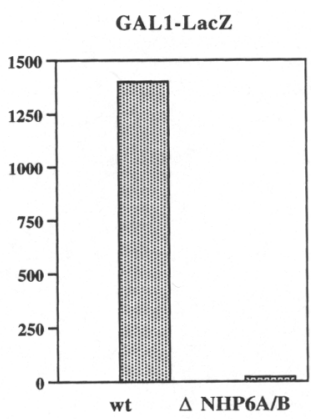

D

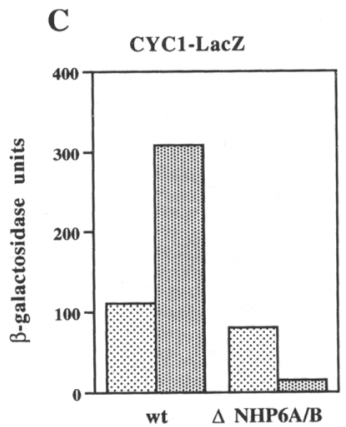

$\mathbf{E}$

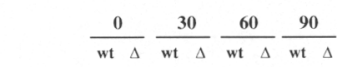

$$
\text { DDR2 } \rightarrow
$$

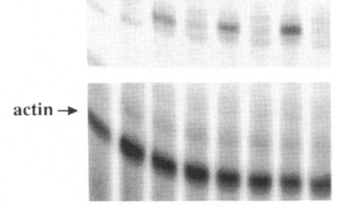

F
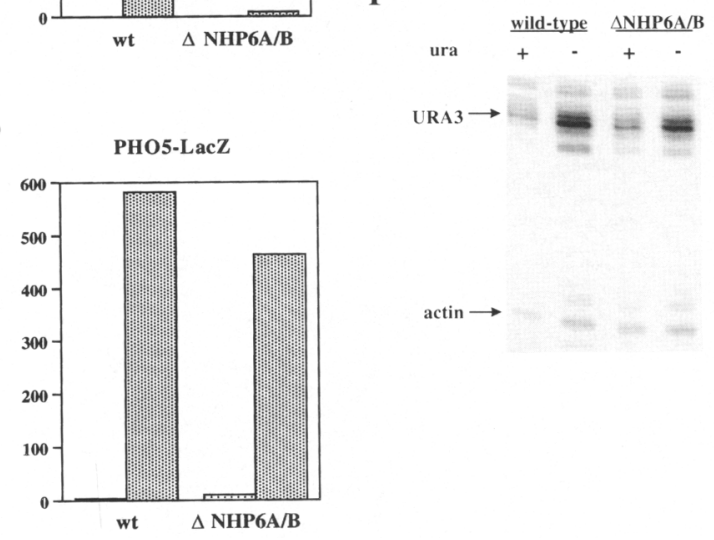

Figure 1. Induction of selected genes in wild-type and $\triangle n h p 6 A / B$ strains. Multiple transformants from each strain were measured in $\beta$-galactosidase assays, and the average of at least two to four transformants is shown. (A) Expression of pLD3 241 (Durrin et al. 1992), a CUP1-LacZ reporter construct, in RJY6022 (wild type) and RJY6024 $(\Delta n h p 6 A / B)$ strains. Expression levels are is shown before (light bars) and after (dark bars) a 30-min exposure to $1 \mathrm{mM} \mathrm{CuSO}_{4}$. $(B)$ Expression of pRY131 (West et al. 1984), a GALl-LacZ reporter construct containing the entire GALl regulatory region, in RJY6244 (wild type) and RJY6252 (Anhp6A) $B)$ strains. Cells were grown in glucose (light bars), then transferred to media containing galactose (dark bars) for $6 \mathrm{hr}$. (C) Expression of pLG $\Delta-312$ (Guarente and Mason 1983|, a CYC1-LacZ reporter construct containing the CYCl UAS and promoter fused upstream of LacZ, in RJY6095 (wild type) and RJY6099 ( $\triangle n h p 6 A / B)$ strains. Expression levels are shown before (light bars) and after (dark bars) a 4 -hr shift from $2 \%$ glucose to $0.05 \%$ glucose. (D) Expression of plW400 (Wan et al. 1995), a PHO5-LacZ reporter construct containing the entire $\mathrm{PHO} 5 \mathrm{regu}-$

latory region upstream of the LacZ gene, in RJY6018 (wild type) and RJY6020 (Anhp6A/B) strains. Cells were induced for 6 hr in phosphate-free media. (Light bars) Before induction; (dark bars) after induction. (E) Expression levels of the DDR2 transcript in SEY6210 (wild type, wt) and RJY6012 $(\Delta \mathrm{nhp} 6 \mathrm{~A} / \mathrm{B}, \Delta)$ strains. Levels of DDR2 RNA and an actin control are shown for uninduced cells $(0)$, and 30,60 , and 90 min after exposure to methyl methanesulfonate $(0.7 \%$ final concentration). $(F)$ Expression levels of the URA3 transcript in RJY6095 (wild type) and RJY6099 $(\Delta \mathrm{nhp} 6 \mathrm{~A} / \mathrm{B})$ strains. Cells were grown in SD complete media $(+\mid$, then transferred into SD media minus uracil for $4.5 \mathrm{hr}(-)$.

We also measured transcript levels from the Tyl gene, which is expressed constitutively (Curcio et al. 1990), and found only a small difference between the wild-type and mutant cells (Table 1). The slower growth rate of the $\Delta n h p 6 A / B$ strain may be responsible for the $\sim 20 \%$ decrease in Tyl mRNA levels.

Table 1 summarizes all of these in vivo transcription results for both the wild-type and $\triangle n h p 6 A / B$ strains and shows that the variability in gene expression in the double knock-out strain does not seem to be correlated with a particular transcriptional activator. For instance, the copper-binding regulatory protein ACE 1 functions at both the yeast metallothionein (CUP1) (Evans et al. 1990) and superoxide dismutase 1 (SOD1) (Gralla et al. 1991) genes, yet CUP1 showed no induction in the $\Delta n h p 6 A / B$ strain and SOD1 showed a nearly wild-type level of induction. Thus, the dependence on NHP6A/B does not appear to be related to the function of, or a change in, the in vivo levels of ACE1.

Likewise, the 65-fold lower expression of GALl cannot be attributable to a change in GAL4 levels or activity by the loss of NHP6A/B, as activation of promoters containing synthetically derived GAL4-binding sites (e.g., GAL4-HIS3; see Fig. 3B below) are unaffected. Moreover, three of the genes listed, DDR2, DDR48, and UBI4, use a common upstream activation sequence (UAS) element for regulation by DNA damage (Treger et al. 1988;
Kobayashi and McEntee 1993), yet each of these responded differently to the methyl methanesulfonate exposure in the $\Delta n h p 6 A / B$ strain. As mentioned above, DDR2 yielded very little activation in the mutant cells, but DDR48 exhibited a moderate induction of 5.3-fold compared with 10.9-fold in wild type, and expression of UBI4 was near wild-type levels with an induction of 3.1 compared with 3.9 (see Table 1). The location of the gene either on a plasmid (CUP1, CYCl, GALl, HO, PHO5, URA3) versus on the chromosome (DDR2, DDR48, UBI4, SOD1, Tyl) also did not seem to determine the specificity of the effect.

\section{Effect of NHP6A/B is not dependent on the distance} between the UAS and TATA elements

In the Hin inversion system, assembly factors like $\mathrm{HU}$, HMG1/2, or NHP6A/B are required primarily to facilitate interactions between proteins bound at the recombination sites and the enhancer when one of the intervening DNA segments is shorter than $\sim 100$ bp (Haykinson and Johnson 1993; Paull et al. 1993). In this case, without an additional DNA-bending factor, the inherent stiffness of short segments of DNA is believed to discourage interactions between the proteins. Therefore, we tested whether the distance between the core promoter 
Paull et al.

Table 1. Summary of in vivo transcription data

\begin{tabular}{lccccc}
\hline Gene & Strain $^{\mathrm{a}}$ & Basal $^{\mathrm{b}}$ & Induced $^{\mathrm{b}}$ & Fold induction $^{\mathrm{c}}$ & Assay \\
\hline CUP1 & wt & 1.1 & 10.7 & 9.7 & LacZ \\
& $\Delta$ & 1.7 & 1.9 & 1.1 & \\
CYC1 & wt & 111 & 309 & 2.8 & LacZ \\
& $\Delta$ & 80 & 15 & 0.2 & \\
DDR2 & wt & 7.7 & 100 & 13.0 & RNA \\
& $\Delta$ & 7.1 & 17 & 2.4 & \\
DDR48 & wt & 9.2 & 100 & 10.9 & RNA \\
& $\Delta$ & 7.2 & 56 & 5.3 & \\
GAL1 & $w t$ & $<0.1$ & 1400 & 14000 & LacZ \\
& $\Delta$ & $<0.1$ & 21 & 210 & \\
PHO5 & wt & 4.1 & 582 & 142 & LacZ \\
& $\Delta$ & 10.5 & 465 & 44 & \\
SOD1 & wt & 25.4 & 100 & 3.9 & RNA \\
& $\Delta$ & 32.9 & 98 & 3.0 & \\
UBI4 & wt & 25.5 & 100 & 3.9 & RNA \\
& $\Delta$ & 29.4 & 90 & 3.1 & \\
URA3 & wt & 22.3 & 100 & 4.5 & RNA \\
& $\Delta$ & 24.1 & 52 & 2.2 & \\
Tyl & wt & N.A. & 100 & N.A. & RNA \\
& $\Delta$ & N.A. & 83 & N.A. & \\
\hline
\end{tabular}

${ }^{a}$ For each gene measured, levels of basal and induced transcript levels from wild-type $(w t)$ and $\Delta n h p 6 A / B(\Delta)$ strains are shown. ${ }^{b}$ For genes measured by LacZ fusions, $\beta$-galactosidase units are given. For genes measured by RNA, levels of primer extension products were determined using a PhosphorImager and calculated in relation to actin transcripts. The highest level of specific gene transcript in each case was designated as 100 (arbitrary units). For genes measured from plasmids, multiple transformants were measured for each strain and an average of representative results are given. For Ty1, constitutive expression levels were measured, so basal levels and fold-induction are not given (N.A.). For details on cell growth and assay conditions, see Materials and Methods.

cFold induction is the ratio of induced vs. basal levels.

region and the UAS has any effect on the level of transcription in the $\triangle n h p 6 A / B$ strain. To do this we used the CUP1 UAS because it requires only one transcriptional activator, ACEl, which is expressed constitutively (Szczypka and Thiele 1989) and becomes active only in the presence of copper (Evans et al. 1990). In addition, ACE1mediated activation of CUPl is not sensitive to the metabolic state of the cell (Hottiger et al. 1994) and requires only a 30 -min induction; therefore, it should not yield indirect effects attributable to the impaired growth of the mutant strain or to defects in the expression of auxiliary proteins.

As shown in Figure 2A, variants of the CUP1-LacZ plasmid were constructed in which the length of DNA between the UAS and the TATA box is increased from the normal $31 \mathrm{bp}$ to 41,89 , or $151 \mathrm{bp}$. The basal level of transcription was increased in these constructs as a result of the insertion of a restriction site just downstream of the UAS, but a 3- to 10-fold activation was still observed in the wild-type strain. Overall expression levels decreased as the distance was increased, but the fold activation increased in the wild-type strain with the UAS region moved farther away from the core promoter. In
A
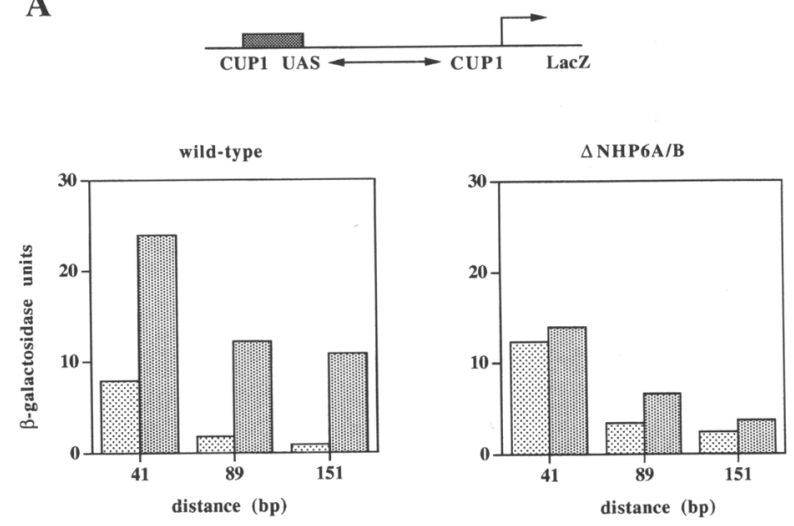

B
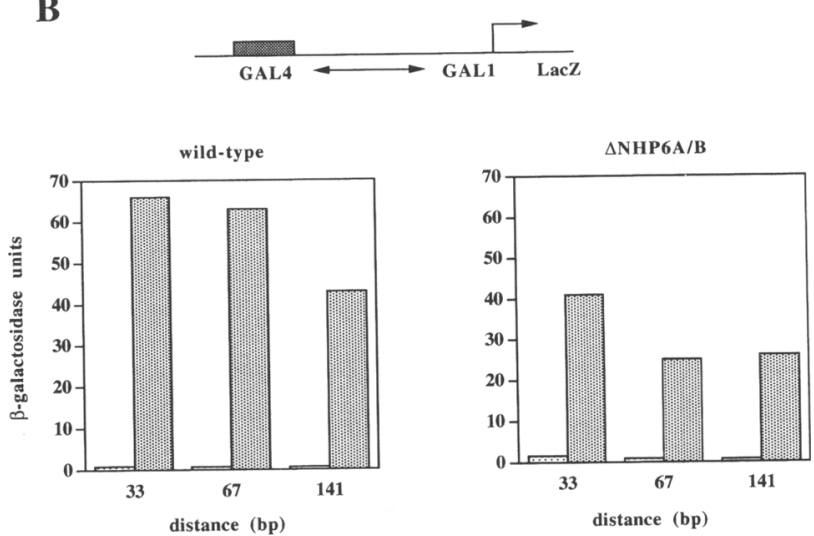

Figure 2. Induction of CUPI-LacZ and GAL1-LacZ derivatives with altered spacing between the UAS and TATA regions. (A) $\beta$-Galactosidase levels are shown for three different CUP1LacZ constructs containing 41 (pRJ1264), 89 (pRJ1272), or 151 bp (pRJ1276) between the CUP1 UAS and the TATA box (measured from the middle of the closest ACE1-binding site to the first $T$ in the TATA box) in wild-type strains RJY6223, RJY6225, and RJY6227, and $\Delta n h p 6 A / B$ strains RJY6229, RJY6231, and RJY6233, respectively. Cells were induced with a 30-min exposure to $1 \mathrm{mM} \mathrm{CuSO}_{4}$. (Light bars) Before induction; (dark bars) after induction. $(B) \beta$-galactosidase levels are shown for three different GAL1-LacZ constructs containing 33 [pMA60-12 (Ruden et al. 1988)], 67 [pMASV15 $2 \mu$ (Ruden et al. 1988)], or 141 bp (pRJ1248) between a single GAL4 site and the TATA box (measured from the middle of the GAL4 site to the first T in the TATA box) in wild-type strains RJY6071, RJY6075, and RJY6079, and $\Delta n h p 6 A / B$ strains RJY6083, RJY6087, and RJY6091, respectively. Cells were induced by $6 \mathrm{hr}$ of growth in galactose. (Light bars) Before induction; (dark bars) after induction. All of the constructs shown were integrated at the URA3 locus in the indicated strains.

contrast, the $\triangle n h p 6 A / B$ strain yielded essentially no activation by copper, even when the UAS was as far as 151 bp away from the TATA box. We also tested a set of constructs containing a single GAL4 site upstream of the GAL1 promoter, modified from a set of constructs described previously (Ruden et al. 1988). These contain 33, 67 , or $141 \mathrm{bp}$ between the activator site and the TATA box, and were induced by 75 - to 90 -fold in the wild-type strain (Fig. 2B). In each case, activated transcription lev- 
els in the $\triangle n h p 6 A / B$ strain were reduced by 40 to $60 \%$ compared with wild-type levels. Therefore, the length of DNA between the UAS region and the core promoter does not appear to dictate whether a promoter will be NHP6A/B dependent or independent.

$N H P 6 A / B$ are required at specific core promoter regions and at the GAL1 UAS

It was plausible that NHP6A/B activity could be required at the UAS or core promoter regions, or both, in affected promoters. To distinguish between these possibilities, we combined UAS and core promoter regions from NHP6A/B-dependent and -independent promoters as shown in Figure 3. Induction of the HIS3 promoter under the control of its native upstream regulatory sites was comparable in the wild-type and $\Delta n h p 6 A / B$ strains, although the levels of induction obtained were low (data not shown). The CUP1 enhancer, when transplanted upstream of the HIS3 core promoter, strongly activated transcription of HIS3 equally well in both strains (Fig. $3 \mathrm{~A} \mid$, despite the inability of the same enhancer region to stimulate expression upstream of the natural CUP1 promoter in the $\triangle n h p 6 A / B$ strain (see Fig. 1A). The CUP1 enhancer region failed to activate transcription in the $\triangle n h p 6 A / B$ strain when positioned upstream of the CYC1 promoter (see Fig. 3C), similar to the effect of NHP6A/B at the natural CYCl gene (see Fig. 1C). On the other hand, a single GAL4 site induced the HIS3 gene equally well in both strains (Fig. 3B). These results indicate that the HIS3 core promoter is independent of NHP6A/B regardless of the upstream UAS, whereas the CUPl and $\mathrm{CYCl}$ core promoters are dependent on NHP6A/B.

Although the function of the CUP1 and PHO5 UAS regions are not affected significantly affected by NHP6A/B, GAL1 UAS activity does require these proteins. The wild-type GALl promoter $\left[(\mathrm{GALl})_{\mathrm{UAS}^{-}}\right.$ GAL1-LacZ] is induced only in the $\triangle n h p 6 A / B$ strain to $1.5 \%$ the level in the NHP6A/B ${ }^{+}$strain /see Fig. 1B and Table 1). On the other hand, induction of the GAL1 promoter by either a single GAL4-binding site (see Fig. 2B) or the PHO5 UAS (Fig. 3D) is only reduced about threefold by the absence of NHP6A/B. Thus, the GALl promoter itself displays about a threefold reduction in activity by the loss of NHP6A/B, but the activity of the GALl UAS is reduced $>20$-fold. Further support for the dependence of the GALl UAS function for NHP6A/B comes from comparison of the activities of a $(\mathrm{GAL} 1\rangle_{\text {UAS }}-$ PHO5-LacZ construct versus the wild-type PHO5 [(PHO5) $)_{\text {UAS }}-$ PHO5-lacZ] control region. The GAL1 UAS was unable to induce detectably the $\mathrm{PHO} 5$ promoter in the NHP6A/B mutant (data not shown), whereas induced levels of transcription from the wildtype PHO5 in the mutant were $80 \%$ of wild-type /see Fig. 1D and Table 1). The substantial basal expression from the (GAL1) UAs-PHO5-LacZ fusion (Wan et al. 1995) may have precluded detection of a low level of induction in these experiments. Nevertheless, the combination of
A

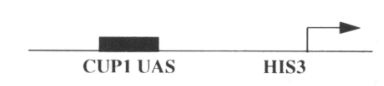

B
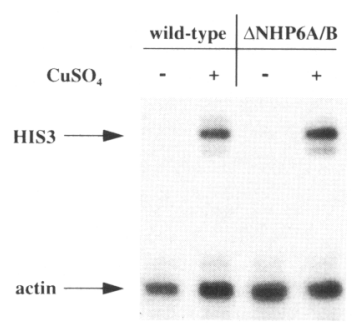

C

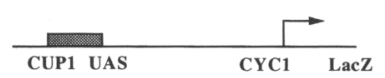

D
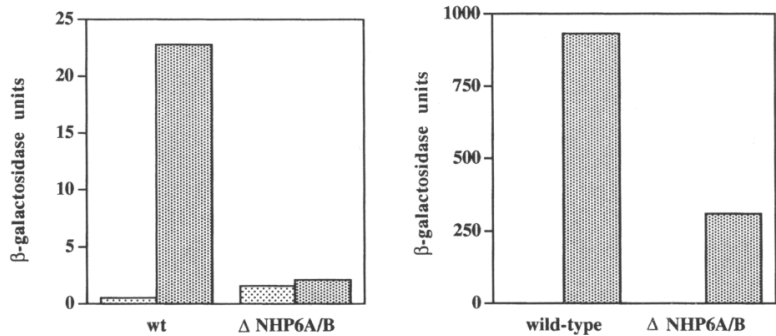

Figure 3. Effects of NHP6A/B on the induction of hybrid genes. (A) Expression of a construct containing the CUP1 UAS upstream of the HIS3 gene (pRJ1283) in RJY6116 (wild type) and RJY6144 $(\Delta n h p 6 A / B)$ strains before and after a 30-min exposure to $1 \mathrm{mM} \mathrm{CuSO}_{4}$. HIS3 and actin primer extension products are indicated. $(B)$ Expression of a construct containing a single GAL4 site upstream of the HIS3 gene (P2) in RJY6112 (wild type) and RJY6196 $(\Delta n h p 6 A / B)$ strains before and after a 6-hr shift from glucose to galactose media. $(C)$ Expression of a hybrid promoter containing the CUP1 UAS upstream of a CYCl-LacZ fusion gene (pRJ1291) in RJY6176b (wild type) and RJY6180 $(\triangle \mathrm{nhp} 6 \mathrm{~A} / B)$ strains by 30 -min exposure to $1 \mathrm{mM} \mathrm{CuSO}_{4}$. (Light bars) Before induction; (dark bars) after induction. (D) Expression of a construct containing the PHO5 UAS upstream of the GAL1 promoter [pJWG113 (Wan et al. 1995)] in RJY6216 (wild type) and RJY6220 ( $\Delta n h p 6 A / B)$ strains before (light bars) and after (dark bars) a 6-hr exposure to phosphate-free media.

results strongly suggests an important positive role of the NHP6A/B proteins on GALl UAS function.

\section{NHP6A/B potentiate transcriptional activation by GAL4-VP16 in vitro}

To begin to decipher the mechanism of NHP6A/B function in gene expression, we performed in vitro transcription reactions using yeast nuclear extracts (Lue and Kornberg 1987) prepared from $\Delta n h p 6 A / B$ cells. These experiments used a GAL1 promoter template containing a single GAL4 binding site upstream. To these reactions we added the modified GAL4-VP16-derived activator VP4 that contains four tandem copies of the VP16 
amino-terminal activation module (Ohashi et al. 1994) plus increasing amounts of NHP6A, and transcription was measured by primer extension. As shown in Figure 4 , the addition of NHP6A stimulated pol II transcription above the level of VP4 alone by three- to five-fold, and did so at a range of VP4 concentrations. No stimulation was observed when NHP6A was added to reactions in the absence of VP4 (data not shown), indicating that NHP6A has no effect on basal transcription in vitro. These reactions contained some chromosomal DNA from the nuclear extract as well as nonspecific competitor poly[d(I-dC)]; therefore, the large amounts of NHP6A added probably do not represent more than a few molecules per specific template. These results also imply that the stimulatory effects by NHP6A/B do not require a chromatin template, because it is unlikely that nucleosomes are being assembled in the yeast extract.

\section{NHP6A promotes assembly of transcription initiation complexes in vitro}

Because the core promoter region appeared to be important in determining the effect of the HMG proteins, we first examined the intrinsic bending of the TATA box regions from both the NHP6A/B-independent HIS3 and NHP6A/B-dependent CYC1 promoters in circular permutation gel electrophoresis assays (Wu and Crothers 1984). Both sets of DNA fragments exhibited a slight bend, but the degree of bending was not significantly different between the two promoters by this method

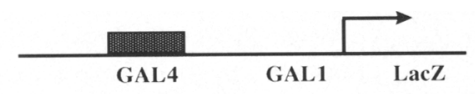

NHP6A (ng) - $\quad$ - 50100200 - $\quad$ - 50100200 - $\quad 50100200$

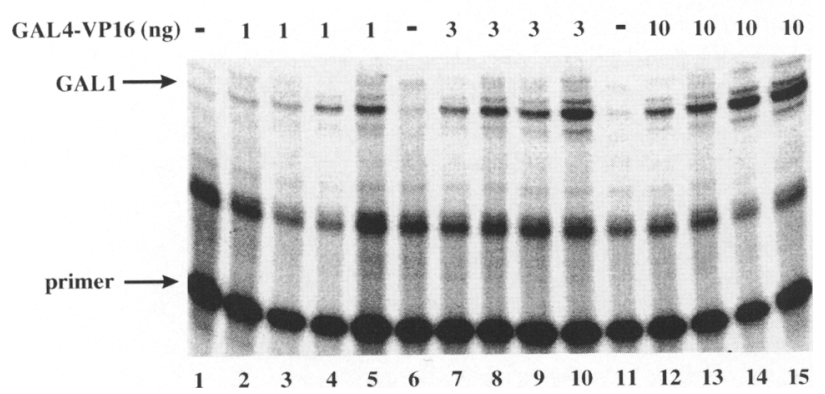

Figure 4. NHP6A stimulates transcription in vitro. GAL4 VP16 and NHP6A protein were added as indicated to in vitro transcription reactions containing yeast nuclear extract obtained from $S$. cerevisiae strain RJY6176a. pMA60-12 (Ruden et al. 1988), described at the top of the figure, was used as the template. Reactions were preincubated for $10 \mathrm{~min}$ at $21^{\circ} \mathrm{C}$, followed by the addition of NTPs, and incubations continued for another $45 \mathrm{~min}$ at $21^{\circ} \mathrm{C}$. RNA was then extracted, subjected to primer extension, and electrophoresed in a $10 \%$ denaturing polyacrylamide gel. The locations of the GALl transcript and excess primer are indicated. The broad band between the GAL1 transcript and the primer is a nonspecific product that appears in reactions without template (data not shown). (data not shown). We also measured the affinity of NHP6A for the TATA box regions of each gene in gel mobility shift assays and each promoter fragment was bound with equivalent affinity by NHP6A (data not shown|, similar to other DNA molecules of random sequence (Paull and Johnson 1995).

To determine whether NHP6A/B could be differentially facilitating the assembly of transcription initiation complexes, we looked for possible interactions between NHP6A and components of the general transcription machinery involved in the early steps of transcription complex assembly. These experiments were performed using both the NHP6A/B-independent HIS3 and -dependent CYC promoters and human-derived transcription proteins, which are highly conserved with their yeast counterparts (Guarente 1995). We tested whether NHP6A could influence the binding of human TBP, TFIIA, and TFIIB on promoter DNA fragments in polyacrylamide gel mobility shift assays.

As shown in Figure 5A, TBP (carboxy-terminal 181 amino acids) and TFIIA formed a complex when incubated with DNA fragments containing the TATA box region from the HIS3 promoter (lane 4) or the CYC promoter (data not shown). NHP6A by itself did not form discrete complexes with the labeled probe (lane 3) because of the excess of competitor DNA in the reaction, and did not form any complexes with TFIIA alone (data not shown). TBP with NHP6A, however, formed a complex when incubated together (complex I, lane 5). When TBP, TFIIA, and NHP6A/B were incubated together they formed this same complex (I), a small amount of the original TBP/TFIIA complex, and a new complex (II) (lane 8). To confirm the presence of NHP6A in complexes I and II, the reactions were incubated further with affinity-purified polyclonal antibody specific for NHP6A/B before gel electrophoresis (Fig. 5B). Addition of moderate amounts of this antibody to a reaction containing TBP, TFIIA, and NHP6A caused a supershift in the migration of complex I (lane 4) with complete elimination of this complex at higher antibody concentrations (lane 5). Levels of complex II are also decreased at the higher concentration of the NHP6A antibody, along with the formation of an apparent supershifted complex (lane 5). Thus, it is likely that both complex I and complex II contain NHP6A. Experiments with NHP6B indicate that it also promotes the formation of complex I and II and, in comparison to NHP6A, favors complex II over complex I in reactions that include TFIIA (Y.-M. Yen and R.C. Johnson, unpubl.).

The binding of TFIIB to the preinitiation complex is the next step after binding of TFIID and TFIIA (Buratowski et al. 1989). It is possible that an architectural factor like NHP6A that is involved in the assembly of this complex might function by modifying the DA complex to be a higher-affinity target for TFIIB, particularly given that TFIIB requires a severely bent DNA for binding (Lee and Hahn 1995; Nikolov et al. 1995). To test this possibility, TFIIB was added to reactions containing TBP, TFIIA, and NHP6A/B (Fig. 5A, lane 9). With this combination, a complex of slightly lower mobility and twofold 


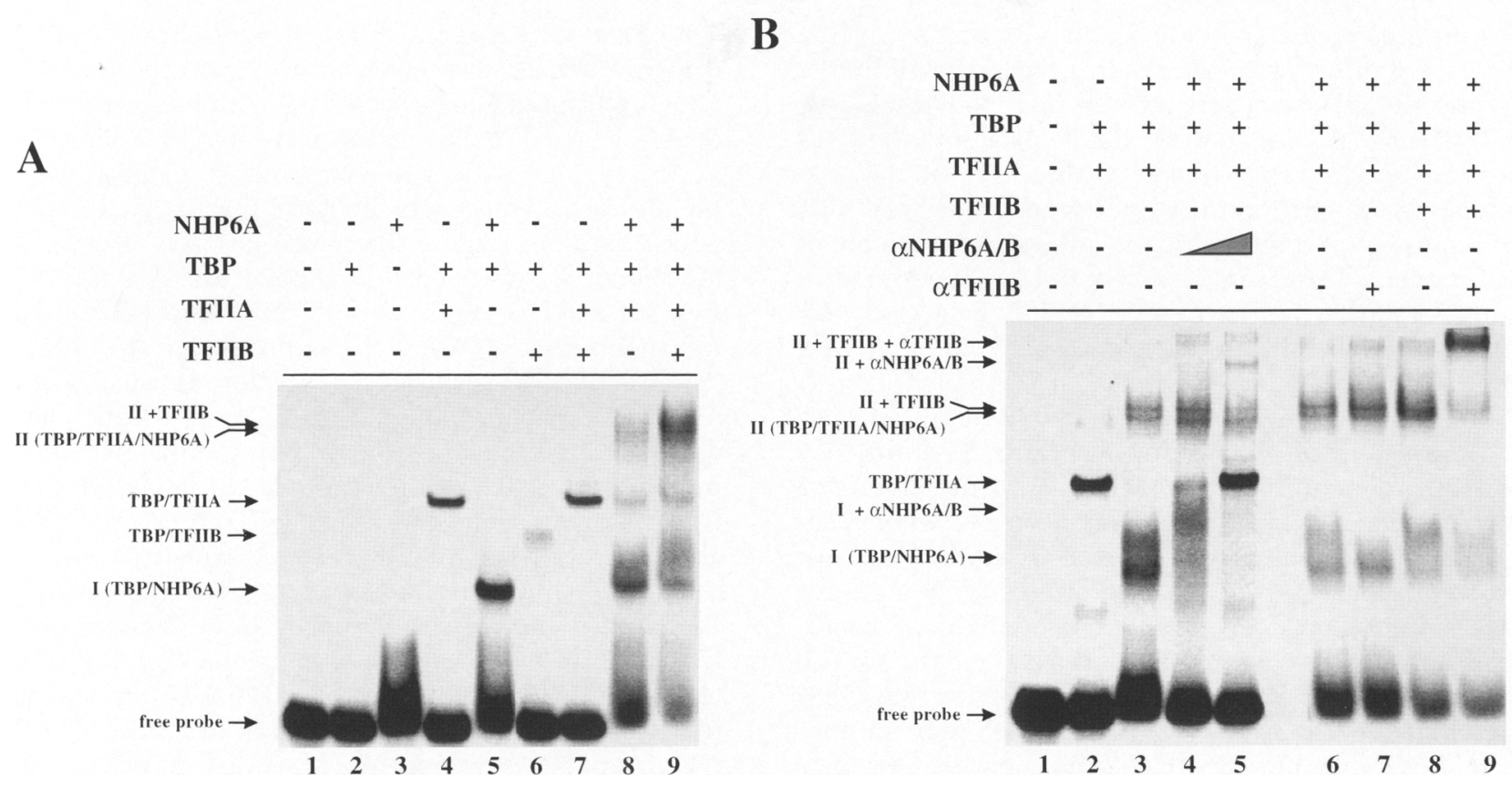

Figure 5. Polyacrylamide gel mobility shift assays with TBP, TFIIA, TFIIB, and NHP6A. (A) Binding reactions containing 5.6 ng of hTBP, $28 \mathrm{ng}$ of hTFIIA, $28 \mathrm{ng}$ of hTFIIB, and $100 \mathrm{ng}$ of NHP6A as indicated were incubated at room temperature for 30 min in the presence of $10 \mu \mathrm{g} / \mathrm{ml}$ poly[d(G-C)] and electrophoresed in a native $5 \%$ polyacrylamide gel. The 85 -bp ${ }^{32} \mathrm{P}$-labeled DNA fragment used contained $62 \mathrm{bp}$ of the HIS3 promoter TATA region. Arrows indicate complexes as described in the text. Under these gel conditions, TBP does not generate a discrete complex with DNA. $(B)$ Binding reactions were per-formed as described in $A$ except for an ad-ditional $30 \mathrm{~min}$ of incubation after the addition of antibodies. $\alpha$ NHP6A/B antibodies $(1.6 \mu \mathrm{g}$ and $3.2 \mu \mathrm{g})$ were added to lanes 4 and 5 , respectively. $\alpha$ TFIIB antibody $(1.0 \mu \mathrm{g})$ was added to lanes 7 and 9 .

or more greater intensity than complex II was formed (see also Fig. 5B, lanes 6,8). In contrast, the addition of the same amount of TFIIB to reactions containing TBP and TFIIA alone yielded only trace amounts of a higherorder complex that migrated slightly slower than the TBP/TFIIA complex (Fig. 5A, lane 7). To confirm the presence of TFIIB, complex II + TFIIB was incubated with TFIIB antibody. As shown in Figure 5B, lane 9, addition of the antibody almost completely converted this complex to an even slower migrating form. Control reactions with anti-TFIIB on complex II without added TFIIB did not produce this supershifted complex (lane 7). Therefore, TFIIB binds preferentially to the TBP/TFIIA/ NHP6A complex as compared with the TBP/TFIIA complex without NHP6A. However, the novel complexes formed with these general transcription factors are probably not the only determinants of the differential effects of NHP6A/B on transcription, because the same complexes formed equally well on a $\mathrm{CYCl}$ promoter fragment (data not shown) as on the HIS3 promoter fragment.

\section{Discussion}

NHP6A/B stimulate activation of pol II transcription from certain promoters in S. cerevisiae

NHP6A/B are abundant chromatin-associated proteins in $S$. cerevisiae that are homologs of the mammalian
HMGl/2 proteins. We have investigated the role of NHP6A/B on gene expression both in vivo and in vitro and found that they have a stimulatory effect on transcriptional activation of a subset of pol II genes. Of the 10 genes listed in Table 1, activated expression of four are severely affected with in vivo levels in the $\Delta n h p 6 A / B$ strain reduced $>80 \%$. These include CUP1, CYC1, GAL1, and DDR2. Activated expression of two genes, URA 3 and DDR 48 , was decreased $\sim 50 \%$ and expression of four genes, PHO5, UBI4, SOD1, and Ty1, was not affected significantly. Basal levels of expression for all of these genes were mostly unchanged in the $\triangle n h p 6 A / B$ strain, indicating that NHP6A/B are functioning primarily in activated transcription. The pattern of NHP6A/B dependence and independence was not correlated with any specific inducer or activator, and was not specific to the location of a gene on a plasmid or in the chromosome.

In vitro transcription assays using extracts from an NHP6A/B-deficient strain also demonstrated a marked stimulation of activated transcription by NHP6A/B. Addition of NHP6A/B resulted in three- to fivefold increased levels of activation at the GAL1 promoter by the GAL4-VP16 activator VP4, but had no effect on basal transcription. The increased activated transcription does not appear to be caused by enhanced binding of the activator to the GAL4 site on the template, as the stimulatory effect of NHP6A/B was observed with a range of VP4 concentrations (Fig. 4). Moreover, footprinting as- 
says did not reveal any changes in VP4 binding in the presence of NHP6A/B, other than a general inhibition of binding and DNase cutting at very high NHP6A/B concentrations (data not shown). Naked plasmid DNA was added as templates in the in vitro transcription assays, suggesting that the stimulatory effects of NHP6A/B do not require chromatin, which is unlikely to assemble in the extracts. However, it is possible that chromatin changes induced by the loss of NHP6A/B in vivo may contribute to the pleiotopic effects of the $\triangle n h p 6 A / B$ mutants.

Thus far, NHP6A/B do not appear to function like the well-characterized chromatin-associated factors involved in silencing (Grunstein et al. 1995), in that repression at the silent mating loci and at the telomeres appears to be normal in the $\Delta n h p 6 A / B$ strain (data not shown). In addition, the absence of NHP6A/B does not cause derepression of genes under noninduced conditions, as has been observed in strains lacking the aminotermini of histones H3 and H4 (Han and Grunstein 1988; Han et al. 1988; Wan et al. 1995). Several other chromatin-related genes in yeast have been identified by their effects at the HO and SUC2 loci, or by the suppression of Ty or $\delta$ element insertions. The fact that transcription driven by the URS1 enhancer from the $\mathrm{HO}$ gene is only slightly reduced in an $\Delta n h p 6 A / B$ strain (data not shown) implies that the many chromatin factors that affect $\mathrm{HO}$ expression are separate from the activity of NHP6A/B.

\section{Requirement for NHP6A/B at the core promoter region}

Our initial model for the NHP6A/B effect on transcription was based on results from the Hin inversion system, in which the prokaryotic DNA-bending protein $\mathrm{HU}$ is required to facilitate assembly of the invertasome, an intermediate complex formed during the reaction (Haykinson and Johnson 1993). When the distance between the enhancer and one of the recombination sites is $<100 \mathrm{bp}$, an assembly protein like HU is necessary to promote formation of the invertasome structure (Haykinson and Johnson 1993). NHP6A/B and HMG1/2 can substitute for $\mathrm{HU}$ in fulfilling this role (Paull et al. 1993; Paull and Johnson 1995|, suggesting that the function of the accessory proteins in this reaction is to bend or kink the DNA strands into a small loop necessary for the assembly of the intermediate structure. Because looping of DNA strands is almost certainly required between transcriptional activators bound at the UAS and general factors bound at the TATA box (Ptashne 1988; Mitchell and Tjian 1989), we tested two different sets of promoter constructs with altered spacing between these regions (Fig. 2). According to the spacing model, we expected to see decreased levels of induction in the $\Delta n h p 6 A / B$ strain when the sites were located close together, and increased levels with greater distance between them. We observed no correlation between distance and induction, however; transcription levels diminished slightly as the UAS was moved farther away in both the wild-type and $\triangle n h p 6 A / B$ strains.
We then tested several different hybrid transcriptional control regions and determined that the effect of NHP6A/B appears to be correlated with the core promoters of particular genes, irrespective of the UAS regions upstream. This is most clearly demonstrated by comparing different constructs containing the CUP1 UAS, which does not require the transcription of other genes for induction by copper (Szczypka and Thiele 1989; Evans et al. 1990), and is not subject to variation with the metabolic state of the cells (Hottiger et al. 1994). A (CUP1) UAS -HIS3 fusion construct, for instance, was induced by exposure to $\mathrm{CuSO}_{4}$ in $\triangle n h p 6 A / B$ cells identically to wild type (Fig. $3 \mathrm{~A}$ ), despite the inability of the mutant strain to support CUP1 UAS induction of the CUP1 promoter (Fig. 1A). The CUP1 UAS was also not able to activate a CYCl-LacZ construct in the $\Delta n h p 6 A / B$ strain (Fig. $3 C$ ), similar to the result with the CYCl promoter under the control of the natural CYC1 UAS (Fig. 1C). Therefore, we conclude that the CUP1 UAS itself is not dependent on NHP6A/B, but is unable to function when located upstream of either the CUP1 or $\mathrm{CYC1}$ promoters. In contrast, the HIS3 promoter is not dependent on NHP6A/B for induction because wild-type levels of activated transcription occur in the $\triangle n h p 6 A / B$ strain with either the CUP1 UAS or a single GAL4 binding site placed upstream of HIS3 (Fig. 3B).

\section{NHP6A/B are required for GAL1 UAS activity}

In the case of the GAL1 gene, NHP6A/B appears to influence the functions of both the UAS region and the core promoter. The GALl regulatory region is very complex, with several proteins involved in activation by the large UAS region (Johnston 1987). Induced expression of the GAL1 regulatory region in the $\Delta n h p 6 A / B$ strain yielded $\beta$-galactosidase levels only $1.5 \%$ that of wild type (Fig. 1B), although this still represents a substantial increase (210-fold) above the extremely low level of basal expression. To decipher the differential effects of NHP6A/B at the GAL1 gene, we tested hybrid regulatory regions containing the GALl core promoter, the GAL1 UAS, or a single GAL4 site in combination with other promoters. From results with (PHO5) UAS - GAL1-LacZ and (GAL4)-GAL1-LacZ constructs we found that the GALl core promoter is 30 to $60 \%$ active in $\triangle n h p 6 A / B$ strains compared with wild-type expression levels. If we consider the GALl core promoter to be $\sim 30 \%$ active in the mutant strain and compare this to the observed expression level of the (GAL1) UAS-GAL1-LacZ fusion in this strain, then the defect specific to the GALl UAS would be responsible for a further 20 -fold decrease. Thus, the estimated induction of another core promoter under the control of the GAL1 UAS, such as (GALl) UAsPHO5-LacZ, would be $\sim 5 \%$ of wild-type levels. When we tested this construct we did not see any induction in the $\Delta n h p 6 A / B$ strain (data not shown). Taken together, our results indicate a $\sim 3$-fold effect of NHP6A/B at the GALl core promoter, a $\sim 20$-fold effect specific to the GAL1 UAS, and no effect with a single GAL4 site. The defect in GAL1 UAS function we have observed in the 
$\triangle n h p 6 A / B$ strain may be attributable to a direct effect at the UAS itself, for instance by a requirement for DNAbending between GAL4 sites to mediate transcriptional synergy. Alternatively, it could be an indirect effect caused by decreased expression of auxiliary proteins involved in GALl UAS function.

Mechanism of NHP6A/B activity within the core promoter region involves assembly of the general transcription machinery

The TATA box sequence is distorted during transcriptional activation because of the widening and bending of the minor groove by TBP binding (Kim et al. 1993a,b). The general transcription factor TFIIA contacts the promoter region just upstream of the TATA box forming a complex with TBP, which has been characterized extensively (Geiger et al. 1996; Stargell and Struhl 1996; Tan et al. 1996). A recent study showed that HMG1/2 stimulated activated transcription on the adenovirus major late promoter by $>10$-fold (Shykind et al. 1995). Significantly, this stimulation was reported to occur only with a subset of promoters, and that HMG2 appeared to act at the step of DA complex formation (Shykind et al. 1995). Shykind et al. reported no apparent changes in gel mobility shift or footprinting assays, however, with the addition of HMG1/2. Because we also have observed an effect of NHP6A/B at a subset of promoters, and have identified the core promoter as one of the determining factors in this effect, it is likely that our in vivo results are related to their in vitro results.

NHP6A/B are distinct from HMG1/2 in that they each have one HMG box domain instead of two, and NHP6A/B bind DNA with much higher stability, as measured by gel mobility shift assays (Paull and Johnson 1995|. Because of this greater stability, NHP6A/B may be able to form detectable complexes with general transcription factors under conditions that do not support stable binding of HMG1/2. Gel mobility shift assays with TBP, TFIIA, and NHP6A did, in fact, yield two new complexes (I and II) that were distinct from that formed with TBP and TFIIA alone (Fig. 5). Complex I was also seen when only TBP and NHP6A were present, suggesting that it contains both these proteins. In agreement with this interpretation, complex I was supershifted by antibodies specific for NHP6A/B. This complex may be equivalent to the HMGl-TBP-DNA complex observed previously that was shown to inhibit transcription by pol II in vitro (Ge and Roeder 1994). However, we have not observed any instances of NHP6A/B acting as a transcriptional repressor in vivo.

Formation of complex II required the presence of TFIIA along with TBP and NHP6A and its migration in the polyacrylamide gel was consistent with the additive contributions of each of the proteins. The presence of NHP6A/B within the complex was implied from the anti-NHP6A supershift, although higher concentrations of antibodies were required to supershift complex II, as compared with complex I, and these levels tended to disrupt the complex (Fig. 5). The higher concentration of
NHP6A/B antibody needed to supershift complex II compared with complex I could be attributable to reduced accessibility of NHP6A within the larger complex owing to steric hindrance by TFIIA. Consistent with an internal location, NHP6A must be added at the start of the reaction to form complex II (data not shown). This further implies that NHP6A cannot remodel a preassembled TBP-TFIIA complex into complex II. Such a complex involving a nonsequence-specific HMG protein has not been observed previously, and demonstrates that the binding of NHP6A to TBP-DNA complexes does not necessarily prevent the binding of TFIIA, as reported previously for HMGl (Ge and Roeder 1994). The presence of nonspecific competitor DNA in these reactions prevents NHP6A from binding by itself to the labeled probe. Therefore, to form complexes I and II, NHP6A must have a higher affinity for the TBP-DNA and TBP-TFIIADNA complexes than for naked DNA.

Significantly, the addition of TFIIB into the binding reaction caused a substantial increase in the intensity of complex II, and also a slight decrease in the mobility of the complex in the gel. The presence of TFIIB within this higher intensity complex was confirmed by the supershift observed with anti-TFIIB (Fig. 5B). In contrast, the addition of TFIIB to reactions containing only TBP and TFIIA had very little effect under these conditions. Thus, TFIIB has a markedly higher affinity for the NHP6A/BTBP-TFIIA complex compared with the TBP-TFIIA complex. Perhaps an NHP6A-induced structural change in the TBP-TFIIA-DNA complex may facilitate TFIIBDNA contacts, which span either side of TBP at the TATA box and require considerable DNA deformation (Lee and Hahn 1995; Nikolov et al. 1995). Because the presence of TFIIB within the preinitiation complex is believed to play a pivotal role in recruiting the remaining transcription factors including pol II (Buratowski et al. 1989), the stimulatory effect of NHP6A/B at this step may be one explanation for the positive role of HMG proteins on transcription.

Shykind et al. (1995) reported that the enhancement by HMG2 on DA complex formation was dependent on the presence of TBP-associated factors (TAFs) and a transcriptional activator. Studies with the Epstein-Barr virus activator ZEBRA/Zta also show an interdependency between activator function and DA complex formation (Lieberman and Berk 1994; Chi et al. 1995), and with the affinity of TFIIB for the basal complex (Chi et al. 1995). Experiments with mammalian TFIID and TFIIA preparations indicate that NHP6A promotes the formation of a higher order complex on a promoter fragment that is dependent on the presence of an activator /data not shown|. Thus, NHP6A may target the DA complex and distort the DNA in this region in a manner that facilitates the conformational changes induced by activators. Other proteins such as the TAFs may be involved in this process and perhaps contribute to the differential responsiveness of various promoters to NHP6A/B. Recent evidence for nucleosome-like DNA wrapping by TFIID in the presence of TFIIA (Oelgeschläger et al. 1996) suggests a likely role for DNA bending in this process. Future 
experiments with purified transcription components in vitro should yield additional information about the factors responsible for the promoter-specific dependence on the NHP6A/B proteins.

\section{Materials and methods}

Yeast strains

The wild-type strain used for most of the experiments was SEY6210 (Robinson et al. 1988). A $\Delta n h p 6 A$ derivative of SEY6210 was made by transformation with a PCR product containing the $5^{\prime}$ and $3^{\prime}$ ends of the NHP6A gene flanking the URA3 marker from pRS316 (Sikorski and Hieter 1989) (a method communicated by C. Fox and J. Rine, University of California, Berkeley|. This strain was made $\Delta n h p 6 B$ by transformation with a HindIII-NdeI fragment from pRJ1238 (see below) and selection for $\mathrm{LEU}^{+}$colonies, resulting in RJY6009. A ura version of RJY6009 was obtained by selecting for 5-FOAresistant colonies, resulting in RJY6012. The assays with
pRY131 were done in wild-type strain W303-1A and a $\triangle n h p 6 A / B$ version of this strain (constructed in the same way as RJY6009) because the SEY6210 parental strain is gal. The assays with pMA60-12, pMASV15 $22 \mu$, and P2 were done in strains derived from SEY6210 and RJY6012 that were made partially $\mathrm{GAL}^{+}$by transformation with a PCR product containing the TRP1-GAL3 genomic region from W303-1A and selection for $\mathrm{TRP}^{+}$colonies. The protease-deficient strain BJ1991 was made nhp6A::TRP1 by transformation with a NdeI-BamHI fragment from pRJ1280 (see below) and selection for $\mathrm{TRP}^{+}$colonies, and then nhp6B::LEU2 as described above to create RJY6176a. Each chromosomal substitution was confirmed by PCR analysis of genomic DNA. All other strains listed in Table 2 were derived from these strains by transformation with plasmids described below.

\section{Plasmids}

pLD3 241 (Durrin et al. 1992), pRY131 (Yocum et al. 1984), pLG $\Delta-312$ (Guarente and Mason 1983), pJW400 (Wan et al.

Table 2. Saccharomyces cerevisiae strains used in this study

\begin{tabular}{|c|c|c|}
\hline Strain & Genotype & Source \\
\hline SEY6210 & $\begin{array}{l}\text { MAT } \alpha u r a 3-52 \text { leu2-3,112 his3-4200 trp1- } \Delta 201 \\
\text { lys2-801 suc2- } \Delta 9 \text { gal3 }\end{array}$ & Robinson et al. (1988) \\
\hline RJY6009 & SEY6210 nhp6A::URA3 nhp6B::LEU2 & This study \\
\hline RJY6012 & RJY6009 ura ${ }^{-}$ & This study \\
\hline W303-1A & $\begin{array}{l}\text { MATaleu2-3,112 ura3-1 his3-11,15 ade2-1 trp1-1 can1-100 } \\
\text { adl1 }\end{array}$ & $\begin{array}{l}\text { R. Rothstein (Columbia University, } \\
\text { New York, NY) }\end{array}$ \\
\hline RJY6249 & W303-1A nhp6A::URA3 nhp6B::LEU2 & This study \\
\hline RJY6067 & SEY6210 TRP1 GAL3 & This study \\
\hline RJY6068 & RJY6012 TRP1 GAL3 & This study \\
\hline BJ1991 & MAT $\alpha p r b 1-1122$ pep4-3 leu2 trp1 ura3-52 gal2 & Jones (1991) \\
\hline RJY6176a & BJ1991 nhp6A::TRP1 nhp6B::LEU2 & This study \\
\hline RJY6022 & RJY6000 + pLD3 241 (Durring et al. 1992) & This study \\
\hline RJY6024 & RJY6012 + pLD3 241 (Durring et al. 1992) & This study \\
\hline RJY6244 & W303-1A + pRY131 (West et al. 1984) & This study \\
\hline RJY6252 & RJY6249 + pRY131 (West et al. 1984) & This study \\
\hline RJY6095 & SEY6210 + pLG $\Delta-312$ (Guarente and Mason 1983) & This study \\
\hline RJY6099 & RJY6012 + pLG $\Delta-312$ (Guarente and Mason (1983) & This study \\
\hline RJY 6018 & SEY6210 + pJW400 (Wan et al. 1995) & This study \\
\hline RJY6020 & RJY6009 + pJW400 (Wan et al. 1995) & This study \\
\hline RJY6223 & SEY $6210+$ pRJ1264 & This study \\
\hline RJY6225 & SEY6210 + pRJ1272 & This study \\
\hline RJY6227 & SEY6210 + pRJ1276 & This study \\
\hline RJY6229 & RJY $6012+$ pRJ1264 & This study \\
\hline RJY6231 & RJY6012 + pRJ1272 & This study \\
\hline RJY6233 & RJY $6012+$ pRJ1276 & This study \\
\hline RJY6071 & RJY6067 + pMA60-12 (Ruden et al. 1988) & This study \\
\hline RJY6075 & RJY6067 + pMASV15 $22 \mu$ (Ruden et al. 1988) & This study \\
\hline RJY6079 & RJY $6067+$ pRJ1248 & This study \\
\hline RJY6083 & RJY6068 + pMA60-12 (Ruden et al. 1988) & This study \\
\hline RJY6087 & RJY6068 + pMASV15 $2 \mu$ (Ruden et al. 1988) & This study \\
\hline RJY6091 & RJY $6068+$ pRJ1248 & This study \\
\hline RJY6116 & SEY $6210+$ pRJ1283 & This study \\
\hline RJY6144 & RJY $6012+$ pRJ1283 & This study \\
\hline RJY6176b & SEY6210 + pRJ1291 & This study \\
\hline RJY6180 & RJY6012 + pRJ1291 & This study \\
\hline RJY6112 & RJY6067 + P2 (C. Brandl) & This study \\
\hline RJY6196 & RJY6068 + P2 (C. Brandl) & This study \\
\hline RJY6216 & SEY6210 + pJWG113 (Wan et al. 1995) & This stydy \\
\hline RJY6220 & RJY6012 + pJWG113 (Wan et al. 1995) & This study \\
\hline
\end{tabular}


1995), and pJWG113 (Wan et al. 1995) have been described elsewhere and were kindly donated by M. Grunstein (University of California, Los Angeles). pMA60-12 and pMASV15 $\Delta 2 \mu$ (Ruden et al. 1988) contain a single GAL4 site upstream of the GAL1 promoter with 33 and 67 bp between the GAL4 and the TATA box, respectively (gift from D. Ruden and M. Ptashne, Harvard University, Cambridge, MA). P2 contains a single GAL4 site upstream of the HIS3 promoter with the proximal GCN4 site removed (gift from C. Brandl, University of Western Ontario, London, Canada).

pRJ1238 contains the LEU2 gene from a StuI and BamHI digest of pRS305 (Sikorski and Hieter 1989) inserted into the same sites in the NHP6B gene in pRJ1229 (Paull and Johnson 1995). pRJ1280 contains the TRP1 gene obtained from a HincII and StuI digest of pRS314 (Sikorski and Hieter 1989) inserted into the EcoRV site in the NHP6A gene in pRJ1281 (NHP6A in pUC18). pRJ1264, pRJ1272, and pRJ1276 are all derivatives of pLD241I (an integrating version of pLD3 241 ) (Durrin et al. 1992). pRJ1264 contains a ClaI site (and an extra 4 extra bp to maintain the helical phase) inserted between the CUP1 UAS and TATA box. pRJ1272 and pRJ1276 were derived from pRJ1264 by ligating 48-bp or 110-bp HpaII fragments from pBR322 into the ClaI site, respectively. pRJ1248 was derived from pMASV15 $\Delta 2 \mu$ (Ruden et al. 1988) by ligating a 74-bp AvrII fragment from phage $\lambda$ into the $X b a$ site located between the GAL4 site and the TATA box. pRJ1283 is the same as P2 (see above) except for the replacement of the GAL4 site with the CUP1 UAS from pLD241I. pRJ1291 is the same as pLGA-312 except for the replacement of the CYC1 UAS between the SmaI and XhoI sites with the CUPI UAS.

The DNA fragments used in gel shifts were from pRJ1328 and pRJ1329, which are pCY7 vectors (Prentki et al. 1987) containing 62-bp segments of the promoters from HIS3 (between BstBI and SacI) and CYCl (between SspI and BclI), respectively, inserted into the polylinker sequence.

\section{Growth conditions}

All in vivo transcription assays were done with cells in log phase $\left.\operatorname{COD}_{600} 0.3-1.2\right)$. Strains were grown in SD media (for strains with plasmids) or in YPD (strains without plasmids or with integrated constructs) for 2 days $(\Delta n h p 6 A / B)$ or 1 day (wild type) before subculturing. SD and YPD are described in Rose et al. $\{1990\}$.

For CUP1 (pLD3 241), CUP1-CYC1 (pRJ1291), SOD1, GAL1 (pRY131), CYC1 (pLGA-312), PHO5 (pJW400), PHO5-GAL1 (pJWG113), DDR2, DDR48, and UBI4 assays, cells were subcultured into fresh YPD media and grown for $6 \mathrm{hr}$. For CUP1, CUP1-CYC1, and SODl assays, $1 \mathrm{mM} \mathrm{CuSO}_{4}$ was then added for $30 \mathrm{~min}$. For GAL1 assays, cells were washed with distilled water then transferred into YP media containing $2 \%$ galactose for an additional $6 \mathrm{hr}$. For CYCl assays, cells were washed with water, transferred into YP media containing $0.05 \%$ glucose, and $\beta$-galactosidase units measured after $4 \mathrm{hr}$. For PHO5 and PHO5GALl assays, cells were washed with water, transferred into $\mathrm{P}_{\mathrm{i}}{ }^{-}$ media (Han et al. 1988), and $\beta$-galactosidase units measured after $6 \mathrm{hr}$. For DDR2, DDR48, and UBI4 assays, methyl methanesulfonate (Sigma) was added to $0.07 \%$ and RNA extracted after 30 to $90 \mathrm{~min}$. For URA3 assays, strains RJY6095 and RJY6099 (containing $2 \mu$ plasmids with the URA3 gene) were grown for 2 days in SD complete media plus casamino acids, washed with water, and transferred into SD media minus uracil (see above) for $4.5 \mathrm{hr}$ before RNA extraction. For Tyl assays, SEY6210 or RJY6012 cells were grown in YPD and harvested in early log phase. For CUP1-HIS3 (pRJ1283) and GAL4-HIS3 (P2) assays, cells were subcultured into minimal complete media and grown for $6 \mathrm{hr}$, then either $1 \mathrm{mM} \mathrm{CuSO}_{4}$ was added for 30 min (CUP1 assays) or cells were washed with water and transferred into minimal complete media containing $2 \%$ galactose for $6 \mathrm{hr}$ (GAL4 assays).

\section{In vivo transcription assays}

RNA extractions were performed by a glass bead/phenol-chloroform method communicated by C. Connolly and S. Sandmeyer. Primer extensions using at least $20 \mu \mathrm{g}$ of RNA were done essentially as described (Carey et al. 1986). Oligonucleotide primers were DDR2: GCGTTACTCGTGGTGTTGG; DDR48: GGTTACATAATCGCCTTGATTG; UBI4: GGGATACCTTCCTTGTCTTG; URA3: TGGTGGTACGAACATCCAAT; actin; GCAGTAAGCGTGAAAAATC; HIS3: CTGGGAAGATCGAGTGC; Tyl: GAAGCACAGGCGCTACCA; GAL1 in vitro transcription assays: TTCCTTTGCGCTAGAATTGAACTCAGGTACA. The oligonucleotide used for SOD1 primer extension has been described (Gralla et al. 1991).

$\beta$-Galactosidase assays were performed as described (Guarente 1983). Multiple transformants were measured for each plasmid in each strain, and the average of at least two to four transformants are reported.

\section{Proteins}

Recombinant NHP6A (Paull and Johnson 1995), hTFIIB (Chi et al. 1995), and VP4 (Ohashi et al. 1994) were purified as described. hTBP (carboxy-terminal core 181 amino acids) and fulllength hTFIIA (Ozer et al. 1994) were obtained as His-tagged recombinant polypeptides (Chi et al. 1995). Yeast nuclear extracts (Lue and Kornberg 1987) were made from RJY6176a using modifications by J. Brickman (Ohashi et al. 1994). Polyclonal rabbit NHP6A/B IgG antibodies were purified by passage through a DEAE-sepharose column and selection on an affigel10 resin coupled with NHP6A, according to the manufacturer's instructions (Bio-Rad). Affinity-purified rabbit anti-TFIIB IgG was provided by $\mathrm{T}$. Chi.

\section{Gel mobility shift and in vitro transcription assays}

Polyacrylamide gel mobility shift assays with TBP, TFIIA TFIIB, and NHP6A were modified from (Ranish and Hahn 1991). Reactions contained $4 \mathrm{~mm}$ Tris- $\mathrm{HCl}(\mathrm{pH} 8.0), 5 \mathrm{~mm} \mathrm{MgCl}_{2}, 4 \%$ glycerol, $0.5 \mathrm{mg} / \mathrm{ml} \mathrm{BSA}, 10 \mu \mathrm{g} / \mathrm{ml}$ of poly $[\mathrm{dG} \cdot \mathrm{dC}], 0.1 \%$ Triton $\mathrm{X}-100$, and various amounts of proteins as indicated, in a $20 \mu \mathrm{l}$ volume. Reactions were incubated for $30 \mathrm{~min}$ at room temperature before loading onto a 5\% acrylamide $19: 1$ acrylamide: bisacrylamide) gel containing $25 \mathrm{~mm}$ Tris- $\mathrm{HCl}$ (pH 8.3) $190 \mathrm{~mm}$ glycine, $5 \mathrm{~mm}$ magnesium acetate, and $2.5 \%$ glycerol, and electrophoresed in the same buffer minus glycerol at $\sim 10 \mathrm{~V} / \mathrm{cm}$ for 3-4 hr at room temperature. Antibodies were incubated with reactions for an additional $30 \mathrm{~min}$ before loading. Transcription reactions were performed essentially as described (Lue and Kornberg 1987; Ohashi et al. 1994) using 25 ng specific template (pMA60-12), and $275 \mathrm{ng}$ poly[d $\cdot \mathrm{dC}$ ] as competitor.

\section{Acknowledgments}

We thank Michael Grunstein for the generous donation of plasmids and Greg Payne for yeast strains and advice. We also thank Doug Ruden, Chris Brandl, and Craig Peterson for plasmids, Suzanne Sandmeyer, Josh Brickman, and Mark Ptashne for protocols, and Sung Pyo for protein purification. This work was made possible by grants from the National Institutes of Health (GM38509 to R.C.J. and GM46424 to M.C.), and an American 
Cancer Society Faculty Research Award to R.C.J.. T.T.P. was supported in part by an Ursula Mandel fellowship and a U.S. Public Health Service National Research Service Award (GM07185)

The publication costs of this article were defrayed in part by payment of page charges. This article must therefore be hereby marked "advertisement" in accordance with 18 USC section 1734 solely to indicate this fact.

\section{References}

Bianchi, M.E., M. Beltrame, and G. Paonessa. 1989. Specific recognition of cruciform DNA by nuclear protein HMG1. Science 243: 1056-1058.

Bonne-Andrea, C., F. Harper, J. Sobczak, and A.-M. De Recondo. 1984. Rat liver HMGl: A physiological nucleosome assembly factor. $E M B O$ J. 3: 1193-1199.

Buratowski, S., S. Hahn, L. Guarente, and P.A. Sharp. 1989. Five intermediate complexes in transcription initiation by RNA polymerase II. Cell 56: 549-561.

Carey, M.F., K. Singh, M. Botchan, and N.R. Cozzarelli. 1986. Induction of specific transcription by RNA polymerase III in transformed cells. Mol. Cell. Biol. 6: 3068-3076

Chi, T., P. Lieberman, K. Ellwood, and M. Carey. 1995. A general mechanism for transcriptional synergy by eukaryotic activators. Nature 377: 254-257.

Costigan, C., D. Kolodrubetz, and M. Snyder. 1994. NHP6A and NHP6B, which encode HMGl-like proteins, are candidates for downstream components of the yeast SLT2 mitogen-activated protein kinase pathway. Mol. Cell. Biol. 14: 23912403.

Curcio, M.J., A.M. Hedge, J.D. Boeke, and D.J. Garfinkel. 1990. Ty RNA levels determine the spectrum of retrotransposition events that activate gene expression in Saccharomyces cerevisiae. Mol. Gen. Genet. 220: 213-221.

Durrin, L.K., R.K. Mann, and M. Grunstein. 1992. Nucleosome loss activates CUP1 and HIS3 promoters to fully induced levels in the yeast Saccharomyces cerevisiae. Mol. Cell. Biol. 12: 1621-1629.

Evans, C.F., D.R. Engelke, and D.J. Thiele. 1990. ACEl transcription factor produced in Escherichia coli binds multiple regions within yeast metallothionein upstream activation sequences. Mol. Cell. Biol. 10: 426-429.

Ge, H. and R.G. Roeder. 1994. The high mobility group protein HMGl can reversibly inhibit class II gene transcription by interaction with the TATA-binding protein. $/$. Biol. Chem. 269: 17136-17140

Geiger, J.H., S. Hahn, S. Lee, and P.B. Sigler. 1996. Crystal structure of the yeast TFIIA/TBP/DNA complex. Science 272: 830-836.

Gralla, E.B., D.J. Thiele, P. Silar, and J.S. Valentine. 1991. ACEl, a copper-dependent transcription factor, activates expression of the yeast copper, zinc superoxide dismutase gene. Proc. Natl. Acad. Sci. 88: 8558-8562.

Grosschedl, R., K. Giese, and J. Pagel. 1994. The HMG domain: A DNA-binding motif that modulates DNA structure Trends Genet. 10: 94-100.

Grunstein, M., A. Hecht, G. Fisher-Adams, J. Wan, R.K. Mann, S. Strahl-Bolsinger, T. Laroche, and S. Gasser. 1995. The regulation of euchromatin and heterochromatin by histones in yeast. I. Cell. Sci. 19: 29-36.

Guarente, L. 1983. Yeast promoters and lacZ fusions designed to study expression of cloned genes in yeast. Methods Enzymol. 101: 181-191.
1995. Transcriptional coactivators in yeast and beyond Trends Biochem. Sci. 20: 517-521.

Guarente, L. and T. Mason. 1983. Heme regulates transcription of the $\mathrm{CYCl}$ gene of $S$. cerevisiae via an upstream activation site. Cell 32: 1279-1286.

Han, M. and M. Grunstein. 1988. Nucleosome loss activates yeast downstream promoters in vivo. Cell 55: 1137-1145.

Han, M., U-J. Kim, P. Kayne, and M. Grunstein. 1988. Depletion of histone $\mathrm{H} 4$ and nucleosomes activates the PHO5 gene in Saccharomyces cerevisiae. EMBO I. 7: 2221-2228.

Haykinson, M.J. and R.C. Johnson. 1993. DNA looping and the helical repeat in vitro and in vivo: Effect of HU protein and enhancer location on Hin invertasome assembly. EMBO J. 12: 2503-2512.

Hottiger, T., P. Furst, G. Pohlig, and J. Heim. 1994. Physiological characterization of the yeast metallothionein (CUP1) promoter, and consequences of overexpressing its transcriptional activator, ACE1. Yeast 10: 283-296.

Johns, E.W. 1982. The HMG chromosomal proteins. Academic Press, New York, NY.

Johnston, M. 1987. A model fungal gene regulatory mechanism: The GAL genes of Saccharomyces cerevisiae. Microbiol. Rev. 51: 458-476.

Jones, E.W. 1991. Tackling the protease problem in Saccharomyces cerevisiae. Methods Enzymol. 194: 428-453.

Kim, Y., J.H. Geiger, S. Hahn, and P.B. Sigler. 1993a. Crystal structure of a yeast TBP/TATA-box complex. Nature 365: 512-520.

Kim, J.L., D.B. Nikolov, and S.K. Burley. 1993b. Co-crystal structure of TBP recognizing the minor groove of a TATA element. Nature 365: 520-527.

Kobayashi, N. and K. McEntee. 1993. Identification of cis and trans components of a novel heat shock stress regulatory pathway in Saccharomyces cerevisiae. Mol. Cell. Biol. 13: $248-256$

Kolodrubetz, D. and A. Burgum. 1990. Duplicated NHP6 genes of Saccharomyces cerevisiae encode proteins homologous to bovine high mobility group protein 1. I. Biol. Chem. 265: 3234-3239.

Kuehl, L., B. Salmond, and L. Tran. 1984. Concentrations of high-mobility-group proteins in the nucleus and cytoplasm of several rat tissues. J. Cell Biol. 99: 648-654.

Landsman, D. and M. Bustin. 1991. Assessment of the transcriptional activation potential of the HMG chromosomal proteins. Mol. Cell. Biol. 11: 4483-4489.

- 1993. A signature for the HMG-1 box DNA-binding proteins. Bioessays 15: 539-545.

Lavoie, B.D. and G. Chaconas. 1994. A second high affinity HU binding site in the phage $\mathrm{Mu}$ transpososome. J. Biol. Chem. 269: $15571-15576$.

Lee, S. and S. Hahn. 1995. Model for binding of transcription factor TFIIB to the TBP-DNA complex. Nature 376: 609-612.

Lieberman, P.M. and A.J. Berk. 1994. A mechanism for TAFs in transcriptional activation: Activation domain enhancement of TFIID-TFIIA-promoter DNA complex formation. Genes \& Dev. 8: 995-1006.

Love, J.J., X. Li, D.A. Case, K. Giese, R. Grosschedl, and P.E. Wright. 1995. Structural basis for DNA bending by the architectural transcription factor LEF-1. Nature 376: 791-795.

Lue, N.F. and R.D. Kornberg. 1987. Accurate initiation at RNA polymerase II promoters in extracts from Saccharomyces cerevisiae. Proc. Natl. Acad. Sci. 84: 8839-8843.

Mitchell, P.J. and R. Tjian. 1989. Transcriptional regulation in mammalian cells by sequence-specific DNA binding proteins. Science 245: 371-378.

Nightingale, K., S. Dimitrov, R. Reeves, and A.P. Wolffe. 1996. 
Evidence for a shared structural role for HMG1 and linker histones $\mathrm{B} 4$ and $\mathrm{H} 1$ in organizing chromatin. EMBO $J$. 15: $548-561$.

Nikolov, D.B., H. Chen, E.D. Halay, A.A. Usheva, K. Hisatake, D.K. Lee, R.G. Roeder, and S.K. Burley. 1995. Crystal structure of a TFIIB-TBP-TATA-element ternary complex. $\mathrm{Na}$ ture 377: 119-128.

Oelgeschläger, T., C.-M. Chiang, and R.G. Roeder. 1996. Topology and reorganization of a human TFIID-promoter complex. Nature 382: 735-738.

Ohashi, Y., J.M. Brickman, E. Furman, B. Middleton, and M. Carey. 1994. Modulating the potency of an activator in a yeast in vitro transcription system. Mol. Cell. Biol. 14: 2731-2739.

Ozer, J., P.A. Moore, A.H. Bolden, A. Lee, C.A. Rosen, and P.M. Lieberman. 1994. Molecular cloning of the small (gamma) subunit of human TFIIA reveals functions critical for activated transcription. Genes \& Dev. 8: 2324-2335.

Paull, T.T. and R.C. Johnson. 1995. DNA looping by Saccharomyces cerevisiae high mobility group proteins NHP6A/B. $J$. Biol. Chem. 270: 8744-8754.

Paull, T.T., M.J. Haykinson, and R.C. Johnson. 1993. The nonspecific DNA-binding and -bending proteins HMG1 and HMG2 promote the assembly of complex nucleoprotein structures. Genes \& Dev. 7: 1521-1534.

Pil, P.M. and S.J. Lippard. 1992. Specific binding of chromosomal protein HMG1 to DNA damaged by the anticancer drug cisplatin. Science 256: 234-237.

Pil, P.M., C.S. Chow, and S.J. Lippard. 1993. High-mobility group 1 protein mediates DNA bending as determined by ring closures. Proc. Natl. Acad. Sci. 90: 9465-9469.

Prentki, P., M-H. Pham, and D.J. Galas. 1987. Plasmid permutation vectors to monitor DNA bending. Nucleic Acids Res. 15: 10060 .

Ptashne, M. 1988. How eukaryotic transcriptional activators work. Nature 335: 683-689.

Ranish, J.A. and S. Hahn. 1991. The yeast general transcription factor TFIIA is composed of two polypeptide subunits. I. Biol. Chem. 266: 19320-19327.

Read, C.M., P.D. Cary, C. Crane-Robinson, P.C. Driscoll, and D.G. Norman. 1993. Solution structure of a DNA-binding domain from HMG1. Nucleic Acids Res. 21: 3427-3436.

Robinson, J.S., D.J. Klionsky, L.M. Banta, and S.D. Emr. 1988. Protein sorting in Saccharomyces cerevisiae: Isolation of mutants defective in the delivery and processing of multiple vacuolar hydrolases. Mol. Cell. Biol. 8: 4936-4948.

Rose, M.D., F. Winston, and P. Hieter. 1990. Methods in yeast genetics: A laboratory course manual. Cold Spring Harbor Laboratory Press; Cold Spring Harbor, NY.

Ruden, D.M., J. Ma, and M. Ptashne. 1988. No strict alignment is required between a transcriptional activator binding site and the "TATA box" of a yeast gene. Proc. Natl. Acad. Sci. 85: 4262-4266.

Segall, A.M., S.D. Goodman, and H.A. Nash. 1994. Architectural elements in nucleoprotein complexes: Interchangeability of specific and nonspecific DNA binding proteins. $E M B O$ I. 13: 4536-4548.

Shykind, B.M., J. Kim, and P.A. Sharp. 1995. Activation of the TFIID-TFIIA complex with HMG-2. Genes \& Dev. 9: 1354 1365.

Sikorski, R.S. and P. Hieter. 1989. A system of shuttle vectors and yeast host strains designed for efficient manipulation of DNA in Saccharomyces cerevisiae. Genetics 122: 19-27.

Singh, J. and G.H. Dixon. 1990. High mobility group proteins 1 and 2 function as general class II transcription factors. Bio- chem. 29: 6295-6302.

Stargell, L.A. and K. Struhl. 1996. Mechanisms of transcriptional activation in vivo: Two steps forward. Trends Genet. 12: 311-315.

Stelzer, G., A. Goppelt, F. Lottspeich, and M. Meisterernst. 1994. Repression of basal transcription by HMG2 is counteracted by TFIIH-associated factors in an ATP-dependent process. Mol. Cell. Biol. 14: 4712-4721.

Szczypka, M.S. and D.J. Thiele. 1989. A cysteine-rich nuclear protein activates yeast metallothionein gene transcription. Mol. Cell. Biol. 9: 421-429.

Tan, S., Y. Hunziker, D.F. Sargent, and T.J. Richmond. 1996. Crystal structure of a yeast TFIIA/TBP/DNA complex. $\mathrm{Na}$ ture 381: 127-151.

Tjian, R. and T. Maniatis. 1994. Transcriptional activation: A complex puzzle with few easy pieces. Cell 77: 5-8.

Treger, J.M., K.A. Heichman, and K. McEntee. 1988. Expression of the yeast UBI4 gene increases in response to DNA-damaging agents and in meiosis. Mol. Cell. Biol. 8: 1132-1136.

Tremethick, D.J. and P.L. Molloy. 1988. Effects of high mobility group proteins 1 and 2 on initiation and elongation of specific transcription by RNA polymerase II in vitro. Nucleic Acids Res. 16: 11107-11123.

Wan, J.S., R.K. Mann, and M. Grunstein. 1995. Yeast histone H3 and $\mathrm{H} 4 \mathrm{~N}$ termini function through different GAL1 regulatory elements to repress and activate transcription. Proc. Natl. Acad. Sci. 92: 5664-5668.

Weir, H.M., P.J. Kraulis, C.S. Hill, A.R.C. Raine, E.D. Laue, and J.O. Thomas. 1993. Structure of the HMG box motif in the B-domain of HMG1. EMBO J. 12: 1311-1319.

Werner, M.H., J.R. Huth, A.M. Gronenborn, and G.M. Clore. 1995. Molecular basis of human 46X,Y sex reversal revealed from the three-dimensional solution structure of the human SRY-DNA complex. Cell 81: 705-714.

Werner, M.H., A.M. Gronenborn, and G.M. Clore. 1996. Intercalation, DNA kinking, and the control of transcription. Science 271: 778-784.

West, R.W., R.R. Yocum, and M. Ptashne. 1984. Saccharomyces cerevisiae GAL1-GAL10 divergent promoter region: Location and function of the upstream activating sequence $\mathrm{UAS}_{\mathrm{G}}$. Mol. Cell. Biol. 4: 2467-2478.

Wu, H.M. and D.M. Crothers. 1984. The locus of sequencedirected and protein-induced DNA bending. Nature 308: 509-513.

Yocum, R.R., S. Hanley, R. West, and M. Ptashne. 1984. Use of lac $Z$ fusions to delimit regulatory elements of the inducible divergent GAL1-GAL10 promoter in Saccharomyces cerevisiae. Mol. Cell. Biol. 4: 1985-1998. 


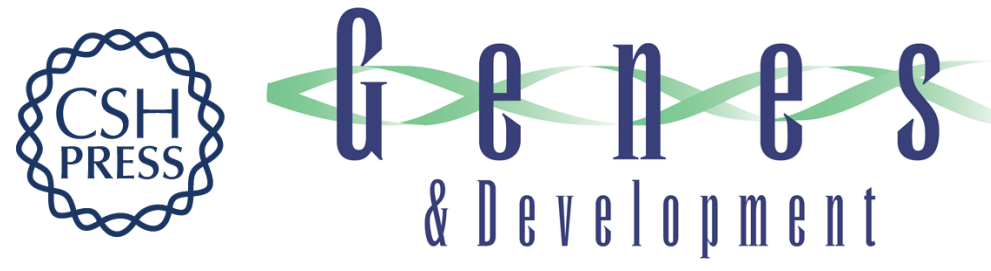

\section{Yeast HMG proteins NHP6A/B potentiate promoter-specific transcriptional activation in vivo and assembly of preinitiation complexes in vitro.}

T T Paull, M Carey and R C Johnson

Genes Dev. 1996, 10:

Access the most recent version at doi:10.1101/gad.10.21.2769

References This article cites 68 articles, 34 of which can be accessed free at:

http://genesdev.cshlp.org/content/10/21/2769.full.html\#ref-list-1

License

Email Alerting Service

Receive free email alerts when new articles cite this article - sign up in the box at the top right corner of the article or click here.

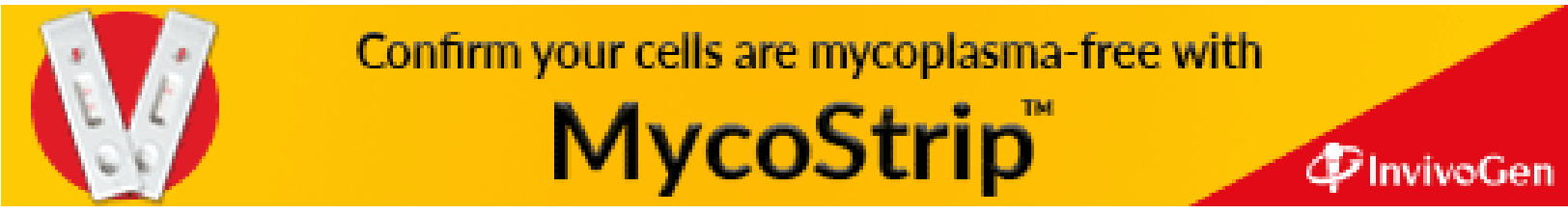

